PAPER

\title{
Are investigations anxiolytic or anxiogenic? A randomised controlled trial of neuroimaging to provide reassurance in chronic daily headache
}

\author{
L Howard, S Wessely, M Leese, L Page, P McCrone, K Husain, J Tong, A Dowson
}

J Neurol Neurosurg Psychiatry 2005;76:1558-1564. doi: 10.1136/jnnp.2004.057851

See end of article for authors' affiliations

Correspondence to:

Dr Louise Howard, Health

Services Research

Department, PO 29

Institute of Psychiatry, De

Crespigny Park, London

SE5 8AF, UK; I'.howard@

iop.kcl.ac.uk

Received

4 November 2004

Revised version received

10 March 2005

Accepted 28 March 2005
Objectives: Aims were to investigate (a) whether neuroimaging in patients with chronic daily headache reassures patients or fails to reassure them and/or worsens outcome, impacting on service use, costs, health anxieties, and symptoms, and (b) whether this reassurance process occurs differentially in patients with different levels of psychological morbidity.

Methods: Design: randomised controlled trial; setting: headache clinic in secondary care, South London; participants: 150 patients fulfilling criteria for chronic daily headache, stratified using the Hospital Anxiety and Depression Scale (HADS); intervention: treatment as usual or the offer of an MRI brain scan; main outcome measures: use of services, costs, and health anxiety.

Results: Seventy six patients were randomised to the offer of a brain scan and 74 patients to treatment as usual. One hundred and thirty seven (91\%) primary care case notes were examined at 1 year, 103 (69\%) patients completed questionnaires at 3 months and $96(64 \%)$ at 1 year. Sixty six $(44 \%)$ patients were HADS positive (scored $>11$ on either subscale). Patients offered a scan were less worried about a serious cause of the headaches at 3 months $(p=0.004)$, but this was not maintained at 1 year; other health anxiety measures did not differ by scan status. However, at 1 year HADS positive patients offered a scan cost significantly less, by $£ 465$ (95\% confidence interval (CI): $-£ 1028$ to $-£ 104)$, than such patients not offered a scan, due to lower utilisation of medical resources.

Conclusions: Neuroimaging significantly reduces costs for patients with high levels of psychiatric morbidity, possibly by changing subsequent referral patterns of the general practitioner.
$M$ edical investigations are often performed to reassure patients they have no serious organic pathology. However, the evidence available is unclear as to whether investigations are reassuring to patients with no clinical evidence of serious pathology, reducing their anxieties and symptoms, or whether they lead to increasing concerns about health and worsen disability. ${ }^{2}$ Several observational studies have suggested that even invasive investigations can reassure patients, ${ }^{3-5}$ but other studies have reported a high level of psychological morbidity and somatic symptoms after standard management with diagnostic tests. ${ }^{6-8}$ These conflicting results may be partly due to methodological differences or confounding factors. ${ }^{2}$ There is some evidence to suggest that patients with additional psychological morbidity are less likely to be reassured by investigations than other patients presenting with similar symptoms. ${ }^{9-11}$ This may be mediated through specific illness perceptions, which may differ in patients with different levels of psychological morbidity. Cognitive models of health anxiety would also predict that patients with high levels of health anxiety would not be reassured by investigations. ${ }^{12}$

There have been few randomised controlled trials investigating diagnostic tests in clinical practice. ${ }^{13-15}$ We have chosen chronic headache to investigate whether tests reassure or not, since chronic headaches are common ${ }^{16}{ }^{17}$ and the consensus of evidence is that neuroimaging is not routinely required on clinical grounds. ${ }^{18}$ However, the US Headache Consortium suggest that a brain scan could be requested to reassure the patient. ${ }^{19}$ Chronic headache is also associated with psychiatric morbidity. ${ }^{20}$ It was therefore hypothesised that patients with chronic daily headache $(\mathrm{CDH})$ and low levels of psychiatric morbidity may be reassured and have a better outcome (that is, lower levels of anxiety, lower utilisation of medical resources, and less headache symptoms) when they receive a brain scan compared with patients who do not. However, patients with $\mathrm{CDH}$ and psychiatric disorder who receive a scan may have a worse outcome than those who do not receive a scan. We therefore aimed to investigate whether current medical practice of using neuroimaging in patients with $\mathrm{CDH}$ does reassure patients, as is intended, or whether it fails to reassure or worsens outcome, that is, increases service contacts and increases anxiety, depending on levels of psychological morbidity.

\section{METHOD \\ Patients}

The study population was consecutive English speaking patients who fulfilled criteria for $\mathrm{CDH}^{21}$ that is, at least 15 days per month of headache for more than 6 months (which can include tension type headache, migraine, and secondary headache due to extensive medication consumption), presenting as new patients to the headache clinic at King's College Hospital in London. Sixty per cent of referrals to this clinic are given diagnoses of $\mathrm{CDH}^{22}$ Referrals were primarily from general practitioners (GPs) and occasionally from neurologists. Patients were excluded if there was a clinical justification for neuroimaging (with the exception of solely providing reassurance) or if there was a medical contraindication to MRI scan. All patients were asked to consent to take part in interviews and follow up questionnaires with data from primary care case notes.

Abbreviations: $\mathrm{CDH}$, chronic daily headache; $95 \% \mathrm{Cl}, 95 \%$ confidence interval; GP, general practitioner; HADS, Hospital Anxiety and Depression Scale; HAQ, Health Anxiety Questionnaire; IPQ-R, Revised Illness Perception Questionnaire; SF36, Medical Outcome Study Short Form 36; VAS, visual analogue scale 


\section{Intervention}

Patients were randomised to receive an offer of a screening MRI scan using a sagittal localiser image followed by a double echo axial series. Computerised tomography was not offered due to the high dose of radiation involved. Letters were sent to patients by the neurologist informing them of normal scan results, as is normal practice in this clinic. Any patients who had abnormal MRI scans were seen by the neurologist and advised appropriately.

Only patients who were randomised to receive a scan were asked for consent to randomisation to neuroimaging. This is therefore an example of post randomisation consent - the Zelen design. ${ }^{23}$ We chose this because patients who were asked to consent to randomisation but not offered a scan might have felt more anxious and less reassured than they would otherwise have done. This could have biased the results and could also have been detrimental to the patients' welfare.

The study received ethical approval from King's Health Care local research ethics committee.

A power calculation (using nQuery Advisor software, Statistical Solutions, Cork, Ireland) showed that 30 patients in four groups would be required. Two pairwise group comparisons of the effect of a scan were of interest: firstly for those with high psychological morbidity and secondly for those with low levels. We anticipated detecting a difference of at least 9 out of 100 points in "worry about health" as measured by the visual analogue scale (VAS). This sample size would give a power of $90 \%$ using a significance level of 0.05 . This level of difference ${ }^{16}$ was based on data from patients who were reassured after normal gastroscopies. ${ }^{11}$ We proposed to include 35 subjects in each cell, to allow for nonparticipation in follow up.

\section{Procedures}

Randomisation based on random permuted blocks was carried out by an independent statistician (ML). A stratified procedure was used, so that patients identified as having a possible psychiatric disorder (detected by the Hospital Anxiety and Depression Scale (HADS) ${ }^{24}$ using a cut off of 11 for possible cases) were randomised separately.

Recruitment, consent, and baseline questionnaires were administered and took 20-30 min to complete. Patients were then seen by the director of the headache clinic who diagnosed patients and decided whether they fulfilled the inclusion criteria. He then opened the sealed envelope already inserted by the research assistant at the back of the case notes and offered or did not offer the intervention. Clinical care continued as usual (that is, explanation of symptoms, verbal reassurance of no serious pathology, and $\mathrm{CDH}$ advice). All patients were given a letter providing information on $\mathrm{CDH}$. Patients were not routinely offered a further appointment as care is usually passed back to the GP in the UK.

Patients completed a semi-structured interview for their medical and psychiatric history and completed the following instruments:

1. Hospital Anxiety and Depression Scale (HADS) ${ }^{24}$ - a self assessment scale for detecting anxiety and depression using 11 as a cut off point. This ensured that HADS positive patients were highly likely to be cases. Anxiety and depression are very closely correlated in the general hospital ${ }^{25}$ and in the community, ${ }^{26}$ and were therefore analysed together.

Primary outcome measures were:

(a) Measures of health anxiety:

2. Visual analogue scales (VAS) of level of worry about health $(0-100)$ and level of illness belief $(0-100) .{ }^{27}$

3. Likert five point scales of anxiety about underlying serious illness ${ }^{11}$ (Do you think there is something seriously wrong which is causing your headaches?; I am concerned about my health; I only think about my health when I go to the doctor for an examination; My health is a big concern in my life; I often think about my health).

4. Health Anxiety Questionnaire (HAQ) ${ }^{28}$ of 21 questions with four subscales: health, worry and preoccupation; fear of illness and death; reassurance seeking behaviour; and extent to which symptoms interfere with a person's life.

(b) Use of services:

5. A modified version of the Client Service Receipt Inventory ${ }^{29}$ was used to record service use over a retrospective 1 year period prior to the consultation. Patients gave this data to the research assistant. Data were also collected from GP records, covering contacts with GPs, neurologists, psychiatrists, psychologists/therapists, other clinicians, and complementary healthcare practitioners. Data were also collected on inpatient stays, visits to accident and emergency departments, imaging, and other investigations.

Secondary outcome measures were:

6. Revised Illness Perception Questionnaire (IPQ-R $)^{30}-\mathrm{a}$ measure of cognitive representations of illness in five scales: timeline, consequences, personal control, treatment control, and illness coherence.

7. Medical Outcome Study Short Form $36(\text { SF36) })^{31}-a$ questionnaire used to measure physical and emotional outcomes and assessing: physical functioning, social functioning, role limitation due to physical problems, role limitation due to emotional problems, mental health, energy and vitality, pain, and general perception of health.

8. In order to prospectively measure headache severity, patients were sent a headache diary 6 weeks before the consultation. This gathered information on the number of days with headache, number of hours, and the intensity of the headache. A headache index ${ }^{32}$ was calculated for each patient as follows: Headache index $=($ no. of hours with headache $) \times($ intensity $) /$ no. of days recorded.

Follow ups were carried out at 3 months and 1 year, using postal questionnaires with the instruments described above, by a second research assistant (JT) who was blind to intervention status. At 1 year, primary care case notes were examined for information on consultation rate, symptoms, further investigations, and contact with secondary and tertiary care. Data were double entered onto a relational database (Access; Microsoft) and then transferred to Stata version 7.0 (SAS, Cary, NC) for analysis.

\section{Statistical analysis}

All randomised subjects (including those who did not wish to receive a scan) who could be followed up were included in an intention to treat analysis. There were no interim analyses or stopping rules. Double sided significance tests were used. Domains with missing data were omitted from the analysis. Linear regression was used for continuous clinical outcome measures and logistic models (binary and ordered) were used for binary and ordered categorical (Likert) measures. Histograms of residuals from linear regressions were plotted

\begin{tabular}{lll} 
Table 1 & \multicolumn{3}{l}{ Baseline characteristics by offer of a scan } \\
\hline & $\begin{array}{l}\text { Not offered } \\
\text { scan }(\mathbf{n}=74)\end{array}$ & $\begin{array}{l}\text { Offered scan } \\
(\mathbf{n}=76)\end{array}$ \\
\hline Gender: male, $n(\%)$ & $57(77 \%)$ & $59(78 \%)$ \\
Ethnic group: white, $\mathrm{n}(\%)$ & $40(54 \%)$ & $45(59 \%)$ \\
Employed, $\mathrm{n}(\%)$ & $40(54 \%)$ & $53(70 \%)$ \\
Marital status: single, $\mathrm{n}(\%)$ & $30(41 \%)$ & $32(42 \%)$ \\
Age, mean (SD) & $40(13.2)$ & $37(11.4)$ \\
HADS score, mean (SD) & $15.8(7.16)$ & $15.4(7.63)$ \\
Headache index, mean (SD) & $35.9(42.1)$ & $33.3(42.0)$ \\
\hline
\end{tabular}


to assess normality. Clinical outcomes presented in the tables are based on the 1 year outcome, for reasons of simplicity and consistency with the economic analysis. We present differences, adjusted differences, and their 95\% confidence intervals between the randomised groups for the group as a whole, and for HADS positive and negative cases separately (since the latter comparisons were specified a priori) also testing for an interaction between HADS status and outcome. In these analyses the outcomes were compared at 1 year, controlling for baseline value and HADS status.

No imputation methods were used for missing values. However, the conclusions about the overall effect of the offer of a scan, over the whole year, on primary outcomes were checked in a longitudinal regression of data at both time points which included random effects for individual patients and time as a further explanatory variable. This analysis maximised the use of the data, in that patients with missing outcomes at 1 year who had valid data at 3 months could be included and vice versa, with the appropriate weight being given to cases with incomplete data. A second sensitivity analysis controlled for sex, age, marital status, and employment status. Adjusted p values presented in tables control only for baseline value and HADS status, if appropriate. Secondary outcomes were analysed separately and results significant at a nominal $\mathrm{p}$ value of 0.05 which were of interest, are presented in the text. This latter group of results should be regarded as exploratory since we have not made any adjustment to them for multiple testing.

The economic evaluation was based on a comprehensive measure of health service costs in the year following randomisation. Service use data were combined with unit costs to enable service costs to be generated. ${ }^{33}$ NHS data were obtained for imaging costs. The intervention costs were estimated using the unit cost of a CT scan (£119), because it was assumed that in routine practice patients would be more likely to receive a CT than an MRI (£286). Productivity costs were not included, although the proportion of patients receiving sick notes from GPs and the number of days off work were measured. Total costs are presented with and without inpatient costs, as the latter have a disproportionate effect on the total. Costs were viewed alongside outcomes but were not combined in a single measure such as an incremental cost effectiveness ratio. Simes' test ${ }^{34}$ was used to adjust for multiple testing. A sensitivity analysis was performed for the total cost analyses, by recalculating subgroup means, having replaced all missing values by the most extreme subgroup mean.

Stata version 7.0 was used (options "test", "regress", and "ologit" for the l year analysis and the "xtreg" for longitudinal analyses). $p$ values for the service use and cost analyses were based on robust standard errors. For cost data, non-parametric bootstrapping with 10000 replications was also used to obtain bias corrected 95\% confidence intervals for differences in mean costs (option "bstrap").

\section{RESULTS}

\section{Patient sample}

Between October 1999 and April 2001150 patients were recruited from the headache clinic, and follow up was completed in April 2002. Figure 1 shows the trial profile. Overall 137 (91\%) GP case notes were examined at 1 year, and $103(69 \%)$ patients were followed up at 3 months and 96 $(64 \%)$ at 1 year.

The majority, $116(77 \%)$, of patients were female. Mean age was 38.1 (SD 12.4) years; 62 (41\%) were single, 85 (57\%) were married or cohabiting, and three $(2 \%)$ were divorced or separated; and $93(62 \%)$ were employed at the time of the initial consultation. A total of $66(44 \%)$ patients were HADS positive, that is, scored $>11$ on either subscale, with a mean score of 15.6 (SD 7.63). There was no statistically significant difference in the proportions of HADS positive patients compared with HADS negative patients by gender $(\mathrm{p}=0.42)$, ethnicity (0.29), or social class $(p=0.23)$. However, there was a trend for HADS positive patients to be single $(p=0.073)$ and they were significantly more likely to be unemployed $(p=0.007)$. The median duration of headache was 24 months with no significant difference for HADS groups $(\mathrm{p}=0.38)$.

The randomised groups were similar in age, marital status, gender, social class, and ethnicity, but patients offered a scan were more likely to be employed (table 1). Of the scans, $97 \%$ were normal and two were abnormal: a posterior fossa arachnoid cyst and a hypothalamic signal flair, neither clinically significant.

Patients who did not respond to questionnaires at 1 year were significantly younger (mean age 34.4, SD 1.34) than responders (mean age 40.1, SD 1.35) $(\mathrm{t}=2.74 ; \mathrm{p}=0.007)$. Non-responders were also more likely to be single $\left(\chi^{2}=6.81\right.$, $\mathrm{p}=0.009)$ and non-white $\left(\chi^{2}=6.73, \mathrm{p}=0.04\right)$. There was no evidence for differences between responders and nonresponders by HADS status or baseline levels of worry about health. The only protocol deviance was non-adherence to intervention status (fig 1). Three patients not allocated to a scan demanded a scan and were sent for a scan by the clinic doctor; five patients were unable to have the scan because of intolerance of the MRI machine.

\section{Primary outcomes}

Patient outcomes were analysed on an intention to treat basis. Table 2 shows the service use outcomes over 1 year from GP notes, and table 3 associated costs. The use of neurologists and psychiatrists was significantly higher for those not offered a scan, whether or not a HADS case, but was particularly high for HADS positive cases. There was a

Table 2 Number (\%) of patients using services during year following randomisation by HADS status and offer of scan

\begin{tabular}{|c|c|c|c|c|c|c|}
\hline & \multicolumn{2}{|c|}{ HADS negative } & \multicolumn{2}{|c|}{ HADS positive } & \multicolumn{2}{|l|}{$\mathbf{p}^{*}$} \\
\hline & $\begin{array}{l}\text { Not offered } \\
(n=41)\end{array}$ & $\begin{array}{l}\text { Offered } \\
(n=43)\end{array}$ & $\begin{array}{l}\text { Not offered } \\
(n=33)\end{array}$ & $\begin{array}{l}\text { Offered } \\
(n=33)\end{array}$ & $\begin{array}{l}\text { Scan } \\
\text { offered }\end{array}$ & $\begin{array}{l}\text { (Interaction } \\
\text { scan } \times \text { HAD status) }\end{array}$ \\
\hline Intervention (scan) & $2(5)$ & $41(95)$ & $1(3)$ & $30(91)$ & & \\
\hline GP & $33(92)$ & 40 (98) & $33(100)$ & $27(100)$ & 0.619 & 0.200 \\
\hline Neurologist & 7 (19) & $1(2)$ & $10(30)$ & $0(0)$ & $<0.001$ & $<0.001$ \\
\hline Psychiatrist/therapist & $2(6)$ & $1(2)$ & $6(18)$ & $0(0)$ & 0.033 & 0.023 \\
\hline Out patient & $16(44)$ & $19(46)$ & $16(48)$ & $11(41)$ & 0.864 & 0.949 \\
\hline Other imaging & $12(33)$ & $8(20)$ & $9(27)$ & $5(19)$ & 0.166 & 0.466 \\
\hline Tests & $16(44)$ & $9(22)$ & $13(39)$ & $12(44)$ & 0.215 & 0.122 \\
\hline In patient care & $4(11)$ & $4(10$ & $6(18)$ & $1(4)$ & 0.274 & 0.374 \\
\hline Other services & $5(14)$ & $5(12)$ & $1(3)$ & $1(4)$ & 1 & 0.305 \\
\hline Sick notes & $4(11)$ & $2(5)$ & $3(9)$ & $4(15)$ & 1 & 0.544 \\
\hline
\end{tabular}




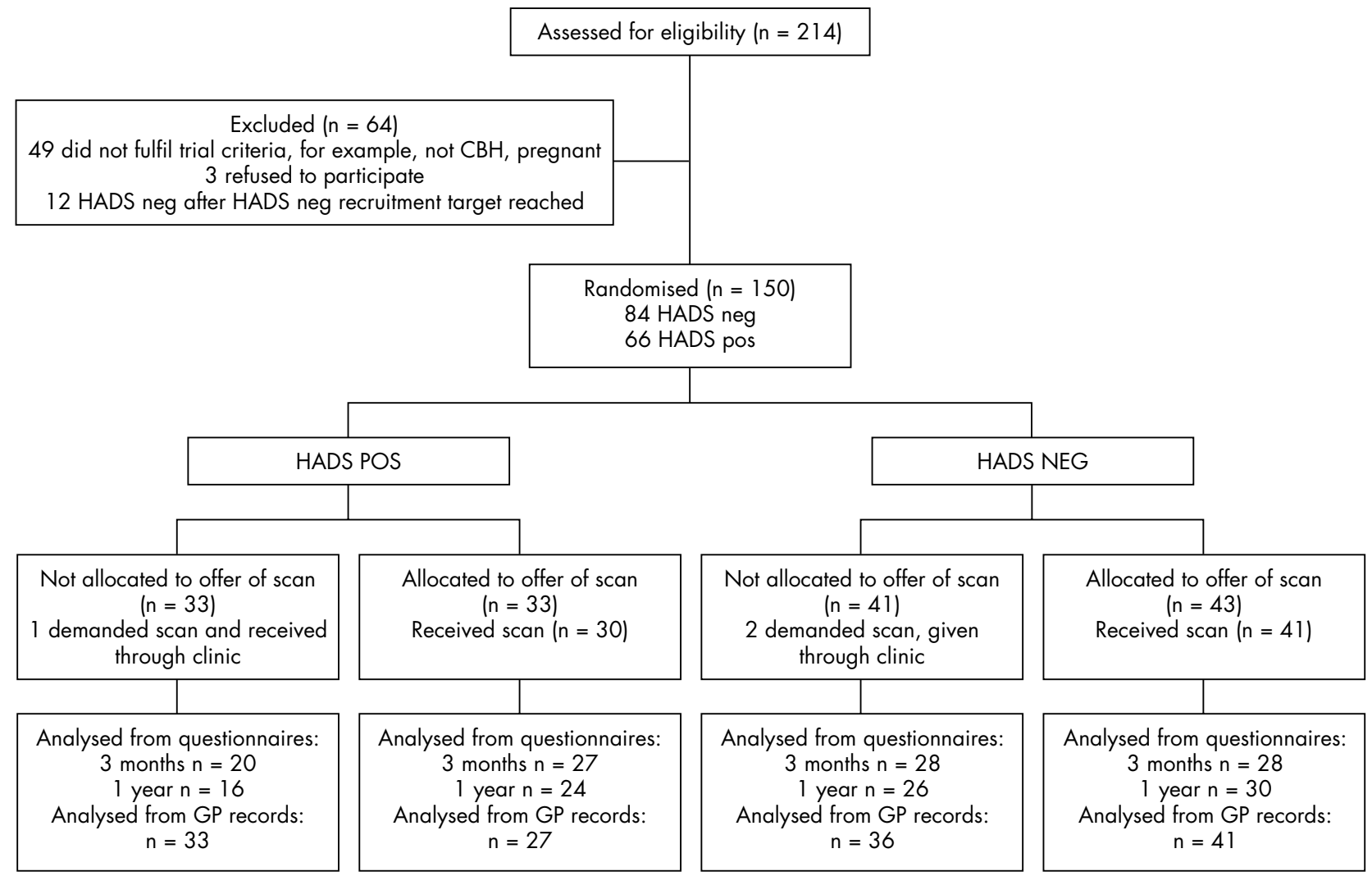

Figure 1 CONSORT diagram showing progress of patients through trial.

significant interaction between HADS status and the offer of a scan for total service costs (table 3 ). This phenomenon was mainly due to differences in inpatient costs $(p=0.073)$ and psychiatrist costs $(p=0.04)$, although after correction for multiple testing this was not significant. One third of HADS positive cases not offered a scan subsequently received a brain scan that year.

Excluding inpatient costs, the estimated mean difference in total costs between HADS positive cases not offered a scan and everyone else was $£ 105$ (95\% CI: $£ 15$ to $£ 248$ ). The mean difference including inpatient costs was $£ 387$ (95\% CI: $£ 16$ to 957). The 13 missing values (five, two, zero, and six cases in the four subgroups, HADS negative/positive, not offered/ offered scan) were replaced by the most extreme mean, that is, that of the HADS positive cases not offered scans (£771).
This increased the mean costs to $£ 403, £ 478, £ 771$, and $£ 391$ for the four groups, respectively, that is, maintaining a marked differential. If we focus on the HADS positive cases, the estimated total cost difference between those offered and those not offered a scan was $-£ 465$ (95\% CI: $-£ 1028$ to $-£ 104)$.

Table 4 shows primary clinical outcomes at 1 year comparing patients offered a scan with those not offered a scan. There was no evidence for any overall effect at 1 year in the VAS or HAQ subscales. At 3 months, the Likert scale "Do you think there is something seriously wrong which is causing your headaches?" did decrease overall ( $p=0.004$, ordered logistic regression), that is, the groups offered a brain scan were reassured, but this was not maintained and there were no other differences between the two randomised groups.

Table 3 Cost of services used during year following randomisation by HADS status and offer of a scan

\begin{tabular}{|c|c|c|c|c|c|c|}
\hline & \multicolumn{2}{|c|}{ HADS negative } & \multicolumn{2}{|c|}{ HADS positive } & \multicolumn{2}{|l|}{$\mathbf{p}^{*}$} \\
\hline & $\begin{array}{l}\text { Not offered } \\
(n=41)\end{array}$ & $\begin{array}{l}\text { Offered } \\
(n=43)\end{array}$ & $\begin{array}{l}\text { Not offered } \\
(n=33)\end{array}$ & $\begin{array}{l}\text { Offered } \\
(n=33)\end{array}$ & $\begin{array}{l}\text { Scan } \\
\text { offered }\end{array}$ & $\begin{array}{l}\text { (Interaction } \\
\text { scan } \times \text { HAD status) }\end{array}$ \\
\hline Intervention & $6(26)$ & $113(25)$ & $4(21)$ & $108(35)$ & & \\
\hline GP & $148(147)$ & 117 (83) & $150(114)$ & 135 (91) & 0.212 & 0.691 \\
\hline Neurologist & 33 (77) & $3(17)$ & $46(82)$ & $0(0)$ & $<0.001$ & 0.423 \\
\hline Psychiatrist/therapist & $5(24)$ & $3(20)$ & $93(242)$ & $0(0)$ & 0.029 & 0.034 \\
\hline Out patient & $80(103)$ & 90 (193) & $81(125)$ & $40(55)$ & 0.592 & 0.228 \\
\hline Other & $6(19)$ & $7(25)$ & $1(4)$ & $2(12)$ & 0.648 & 0.945 \\
\hline Imaging & $11(23)$ & $8(24)$ & 41 (87) & $4(8)$ & 0.017 & 0.036 \\
\hline Test & $8(22)$ & $5(17)$ & $3(4)$ & $6(10)$ & 0.745 & 0.230 \\
\hline In patient care & 61 (177) & $118(643)$ & $352(1121)$ & $9(47)$ & 0.265 & 0.073 \\
\hline \multicolumn{7}{|l|}{ Total service cost† } \\
\hline Including inpatient costs & $352(363)$ & $464(713)$ & 771 (1314) & $306(162)$ & 0.267 & 0.030 \\
\hline Excluding inpatient costs & $292(257)$ & $346(220)$ & 419 (367) & 297 (137) & 0.605 & 0.047 \\
\hline
\end{tabular}


Table 4 Primary clinical outcomes (VAS and HAQ) by offer of scan

\begin{tabular}{|c|c|c|c|c|c|c|c|}
\hline Outcome & $\begin{array}{l}\text { Scan } \\
\text { offered }\end{array}$ & $\mathbf{n}$ & $\begin{array}{l}\text { Baseline } \\
\text { mean (SD) }\end{array}$ & $\begin{array}{l}1 \text { year } \\
\text { mean }\end{array}$ & $\begin{array}{l}\text { Difference at } \\
1 \text { year, } Y-N\end{array}$ & $\begin{array}{l}\text { Adjusted difference at } \\
1 \text { year*, } \mathrm{Y}-\mathrm{N}(95 \% \mathrm{Cl})\end{array}$ & $\begin{array}{l}p^{*} \text { (offer } \\
\text { of scan) }\end{array}$ \\
\hline \multirow[t]{2}{*}{ VAS worry } & $N$ & 42 & $59.8(32.2)$ & 42.9 & -0.12 & $-4.47(-15.27$ to 6.33$)$ & 0.41 \\
\hline & $Y$ & 54 & $68.6(25.4)$ & 42.8 & & & \\
\hline \multirow{4}{*}{$\begin{array}{l}\text { HAQ health, worry and } \\
\text { preoccupation } \\
\text { HAQ fear of illness }\end{array}$} & $\mathrm{N}$ & 34 & $6.91(4.45)$ & 6.47 & -0.43 & $0.22(-1.26$ to 1.70$)$ & 0.77 \\
\hline & Y & 48 & $5.69(4.20)$ & 6.04 & & & \\
\hline & $N$ & 33 & $4.88(3.71)$ & 4.67 & -0.21 & $0.31(-0.84$ to 1.45$)$ & 0.60 \\
\hline & $\mathrm{Y}$ & 50 & $4.10(4.03)$ & 4.46 & & & \\
\hline \multirow{4}{*}{$\begin{array}{l}\text { HAQ reassurance seeking } \\
\text { behaviour } \\
\text { HAQ life interference }\end{array}$} & $N$ & 35 & $1.71(1.58)$ & 2.26 & -0.47 & $-0.39(-0.93$ to 0.16$)$ & 0.16 \\
\hline & $\mathrm{Y}$ & 50 & $1.56(1.43)$ & 1.78 & & & \\
\hline & $N$ & 33 & $4.03(2.74)$ & 2.91 & -0.18 & $-0.20(-1.12$ to 0.72$)$ & 0.66 \\
\hline & $\mathrm{Y}$ & 51 & $4.04(2.10)$ & 2.73 & & & \\
\hline
\end{tabular}

There was no evidence that the effect of offering a scan differed between the two HADS groups (table 5). The results of an analysis using both time points for the VAS and HAQ scales showed very similar results to those presented for 1 year, as did analyses controlling for age, sex, marital status, and employment status.

Of the five Likert scales (not shown in the table), only "I only think about my health when I go to the doctor for an examination" showed any trend to interaction at 1 year $(p=0.071)$. The HADS positive cases tended to increase (indicating more health concern) and HADS negative tended to decrease after the offer of a scan.

\section{Secondary outcomes}

The headache index was highly skewed, and differed markedly between the HADS positive and HADS negative cases at baseline, with median scores at 1 year for HADS positive and negative cases of 22 and 14, respectively. At 1 year, the medians for HADS positive cases reduced from 22 to 10 where a scan was offered but remained high at 20 where no scan was offered, whereas the HADS negative cases reduced among both those offered and not offered a scan, to 6 and 9, respectively. The interaction term in a regression on $\log$ transformed headache indices was borderline at $\mathrm{p}=0.06$.

For the IPQ-R scales, only the "timeline" showed any evidence for interaction $(p=0.05)$, and only at 3 months. The HADS positive cases had similar scores (adjusted mean difference at 3 months 1.09 (95\% CI: -1.66 to 3.84 ) whether or not offered a scan, whereas the adjusted mean difference for HADS negative cases offered a scan compared to those not offered a scan was -2.13 ( $95 \%$ CI: to -4.20 to -0.06 ).

For the SF36 scales, there was little evidence for differences either overall or for each HADS group separately, except for energy and vitality which was higher overall in the two groups offered scans (overall adjusted difference 7.12, 95\% CI: 1.96 to 12.27 ).

\section{DISCUSSION}

Our results show that neuroimaging temporarily reassures patients with $\mathrm{CDH}$ about the cause of their headaches at 3 months, but this effect is not sustained by the 1 year follow up. The scan also did not improve most other measures of health anxiety, illness perceptions, or quality of life. We had predicted increases in anxiety for patients with higher psychological morbidity offered a brain scan on the basis of cognitive models of anxiety ${ }^{12}$; according to this model reassurance, far from reducing anxiety, would increase it. However, HADS positive patients offered a scan showed little exacerbation of health related anxiety other than more health concern on one Likert measure. Even more unexpectedly, HADS positive patients used fewer services when offered a scan compared with HADS positive patients not offered a scan and to a lesser extent than HADS negative patients. This was primarily due to fewer contacts with neurologists and psychiatrists. In addition, a third of HADS positive patients not offered a scan in this clinic had scans elsewhere in the following year. This probably reflects the high level of expectation that patients now have of secondary care where

Table 5 Primary clinical outcomes (VAS and HAQ) at 1 year by HADS status and scan offer

\begin{tabular}{|c|c|c|c|c|c|c|c|}
\hline Outcome & $\begin{array}{l}\text { HADS } \\
\text { status }\end{array}$ & $\begin{array}{l}\text { Scan } \\
\text { offered }\end{array}$ & $\begin{array}{l}\text { Baseline } \\
\text { mean }\end{array}$ & $\begin{array}{l}1 \text { year } \\
\text { mean }\end{array}$ & $\begin{array}{l}\text { Difference at } \\
1 \text { year, } Y-N\end{array}$ & $\begin{array}{l}\text { Adjusted difference at } \\
1 \text { year*, } \mathrm{Y}-\mathrm{N}(95 \% \mathrm{Cl})\end{array}$ & $\begin{array}{l}\text { p* (interaction } \\
\text { scan } \times \text { HADS status) }\end{array}$ \\
\hline \multirow[t]{4}{*}{ VAS worry } & \multirow[t]{2}{*}{ Negative } & $\mathrm{N}$ & 52.0 & 38.7 & 1.34 & $-5.40(-19.01$ to 8.21$)$ & \multirow[t]{4}{*}{0.80} \\
\hline & & Y & 66.6 & 40.1 & & \multirow{3}{*}{$-2.7(-22.60$ to 16.10$)$} & \\
\hline & \multirow[t]{2}{*}{ Positive } & $\mathrm{N}$ & 72.5 & 49.6 & \multirow{2}{*}{-3.50} & & \\
\hline & & Y & 71.0 & 46.1 & & & \\
\hline \multirow{4}{*}{$\begin{array}{l}\text { HAQ health, worry } \\
\text { and preoccupation }\end{array}$} & \multirow[t]{2}{*}{ Negative } & $\mathrm{N}$ & 5.76 & 5.33 & \multirow[t]{2}{*}{-0.72} & \multirow[t]{2}{*}{$0.01(-1.78$ to 1.78$)$} & \multirow[t]{4}{*}{0.61} \\
\hline & & $Y$ & 4.77 & 4.62 & & & \\
\hline & \multirow[t]{2}{*}{ Positive } & $\mathrm{N}$ & 8.77 & 8.31 & \multirow[t]{2}{*}{-0.58} & \multirow[t]{2}{*}{$0.45(-2.18$ to 3.08$)$} & \\
\hline & & Y & 6.77 & 7.73 & & & \\
\hline \multirow[t]{4}{*}{ HAQ fear of illness } & \multirow[t]{2}{*}{ Negative } & $\mathrm{N}$ & 4.55 & 4.25 & \multirow[t]{2}{*}{-0.86} & \multirow[t]{2}{*}{$-0.15(-1.54$ to 1.25$)$} & \multirow[t]{4}{*}{0.52} \\
\hline & & Y & 3.36 & 3.39 & & & \\
\hline & \multirow[t]{2}{*}{ Positive } & $\mathrm{N}$ & 5.38 & 5.31 & \multirow[t]{2}{*}{0.51} & \multirow[t]{2}{*}{$0.80(-1.19$ to 2.78$)$} & \\
\hline & & $Y$ & 5.05 & 5.82 & & & \\
\hline \multirow{4}{*}{$\begin{array}{l}\text { HAQ reassurance } \\
\text { seeking behaviour }\end{array}$} & \multirow[t]{2}{*}{ Negative } & $\mathrm{N}$ & 1.43 & 2.05 & \multirow[t]{2}{*}{-0.40} & \multirow{2}{*}{$-0.45(-1.06$ to 0.17$)$} & \multirow[t]{4}{*}{0.78} \\
\hline & & Y & 1.50 & 1.64 & & & \\
\hline & \multirow[t]{2}{*}{ Positive } & $\mathrm{N}$ & 2.14 & 2.57 & \multirow{2}{*}{-0.62} & \multirow{2}{*}{$-0.24(-1.28$ to 0.80} & \\
\hline & & $Y$ & 1.63 & 1.95 & & & \\
\hline \multirow[t]{4}{*}{$\mathrm{HAQ}$ life interference } & \multirow[t]{2}{*}{ Negative } & $\mathrm{N}$ & 3.30 & 2.70 & \multirow[t]{2}{*}{-0.53} & \multirow[t]{2}{*}{$-0.64(-1.79$ to 0.51$)$} & \multirow[t]{4}{*}{0.27} \\
\hline & & Y & 3.55 & 2.17 & & & \\
\hline & Positive & $\mathrm{N}$ & 5.15 & 3.23 & 0.22 & $0.39(-1.21$ to 1.99$)$ & \\
\hline & & $Y$ & 4.68 & 3.45 & & & \\
\hline
\end{tabular}


patients expect a brain scan for a referral for chronic headaches in a headache clinic. Neuroimaging therefore does not appear to be anxiogenic or anxiolytic in patients with or without psychological morbidity but does decrease service costs in HADS positive patients in the year following a headache clinic consultation.

However, we suggest on the basis of the service contact and economics data that scanning HADS positive patients may have reassured one group, namely the referring doctors. It is not possible from this study to elucidate how the interaction between the patient and the family practitioner differed depending on whether or not a patient was scanned, but the presence of a normal scan result appears to enable the GP to manage the patient more effectively and prevent the cycle of further referrals, unnecessary investigations, and potentially inappropriate treatment. This may be because the GP is reassured or because the GP feels legally covered. This study therefore suggests that the GPs, as opposed to the patients, are being reassured by a scan. Many neurologists offer scans to patients with $\mathrm{CDH}$ for reassurance. There are, however, potential risks from neuroimaging including radiation exposure from a CT scan, anaphylaxis from contrast used, and oversedation of claustrophobic patients. ${ }^{35}$ Our study failed to provide evidence that scans are persistently reassuring; there are therefore many reasons to avoid the risks of neuroimaging for reassurance.

This trial's methodological strengths include comparable groups after randomisation, adequacy of the sample size for the GP data and blinding procedures, use of standardised measures, and a study population from all socio-economic groups. Although the trial setting, a secondary referral headache clinic, is not a typical neurology outpatient clinic, the clinical setting used meant that there was no confounding effect of different doctors reassuring patients in different ways. The main methodological limitation was the differential follow up: non-responders may have had worse psychological outcomes than responders, although there were few baseline differences between patients who responded to questionnaires and those who did not. The response rate was lower than expected which meant there was a lack of statistical power for some of the outcome measures, although we achieved a very high level of information from GP case notes. Finally, it is difficult to measure reassurance; our measures were only able to examine some of the possible cognitions and emotions involved in reassurance. Furthermore, single items such as Likert scales may have relatively high imprecision. The HADS score may be too insensitive a measure of severity of the cause of the headache; a design that stratified patients on the basis of a specific worry about the cause of headache might have been preferable.

The main finding of this study is that addition of a scan is associated with lower service costs for patients with $\mathrm{CDH}$ with high levels of psychological morbidity compared with such patients not offered a scan, and patients with low psychological morbidity (with or without scan). The provision of a scan, however, made little difference to overall levels of symptoms, anxiety, and health concerns, whatever the level of psychological morbidity. The implication of this study is that most patients can be effectively reassured and do not benefit from neuroimaging.

However, in certain circumstances neuroimaging may be useful in helping the referrer to manage the patient with $\mathrm{CDH}$. Neuroimaging does not increase anxiety about the cause of the headache and it may be cost effective in helping the physician manage the patients with high levels of psychological morbidity in primary care. The use of a simple screening measure for psychiatric morbidity such as the HADS can be helpful in identifying patients who are likely to need particularly careful reassurance. This study suggests that neuroimaging will not be psychologically harmful to these patients, although it may reassure GPs rather than their patients.

\section{Authors' affiliations}

L Howard, M Leese, P McCrone, Health Services Research Department, Institute of Psychiatry, London, UK

S Wessely, L Page, K Husain, J Tong, Department of Psychological

Medicine, Institute of Psychiatry, London, UK

A Dowson, Headache Clinic, King's College Hospital, London, UK

This study was funded by The Wellcome Trust, grant number GR050178A.

Competing interests: none declared

\section{REFERENCES}

1 Owen JP, Rutt G, Keir MJ, et al. Survey of general practitioners' opinions on the role of radiology in patients with low back pain. Br J Gen Pract 1990;40(332):98-101.

2 Howard LM, Wessely SC. Reassurance reappraised - the role of investigations [editorial]. J Psychosom Res 1996;41:307-11.

3 Hansen JM, Bytzer P, Bondesen S, et al. Efficacy and outcome of an open access endoscopy service. Dan Med Bull 1991;38:288-90.

4 Hungin APS, Thomas PR, Bramble MG, et al. What happens to patients following open access gastroscopy? An outcome study from general practice. Br J Gen Pract 1994;44:519-21.

5 Faxon DP, McCabe CH, Kreigel DE, et al. Therapeutic and economic value of a normal coronary angiogram. Am J Med 1982;73:500-5.

6 Ockene BS, Shay MJ, Alpert JS, et al. Unexplained chest pain in patients with normal coronary arteriograms. N Engl J Med 1980;303(22):1249-52.

7 Potts SG, Bass CM. Psychological morbidity in patients with chest pain and normal or near-normal coronary arteries: a long term follow-up study. Psychol Med 1995;25:339-47

8 McDonald IG, Daly J, Jelinek VM, et al. Opening Pandora's box: the unpredictability of reassurance by a normal test result. $B M J$ 1996;313:329-32.

9 Channer KS, James MA, Papouchado $M$, et al. Failure of a negative exercise test to reassure patients with chest pain. QJM 1987;240:315-22.

10 Fitzpatrick R, Hopkins A. Referrals to neurologists for headaches not due to structural disease. J Neurol Neurosurg Psychiatry $1981 ; 44: 1061-7$.

11 Lucock MP, Morley S, White C, et al. Responses of consecutive patients to reassurance after gastroscopy: results of self administered questionnaire survey. BMJ 1997;315:572-5.

12 Warwick HM. A cognitive-behavioural approach to hypochondriasis and health anxiety. J Psychosom Res 1989;33(6):705-11.

13 Deyo RA, Diehl AK, Rosenthal M. Reducing roentgenography use - can patient expectations be altered? Arch Intern Med 1987;147:141-5.

14 Goodson JD, Lehmann JW, Richter JM, et al. Is upper gastrointestinal radiography necessary in the initial management of uncomplicated dyspepsia? A randomised controlled trial comparing empiric antacid therapy plus patient reassurance with traditional care. J Gen Intern Med 1989:4:367-74.

15 Sox HC Jr, Margulies I, Sox CH. Psychologically mediated effects of diagnostic tests. Ann Intern Med 1981;95:680-5.

16 Schwartz BS, Stewart WF, Simon D, et al. Epidemiology of tension-type headache. JAMA 1998;279:381-3.

17 Castillo J, Munoz P, Guitera V, et al. Epidemiology of chronic daily headache in the general population. Headache 1999;39:190-6.

18 Frishberg BM. The utility of neuroimaging in the evaluation of headache in patients with normal neurologic examinations. Neurology 1994;44(7): 1191-7.

19 Frishberg BM, Rosenberg JH, Matchar DB, et al. Evidence-based guidelines in the primary care setting: neuroimaging in patients with nonacute headache http://www.aan.com/professionals/practice/pdfs/gl0088.pdf (accessed April 2005).

20 Merikangas K. Association between psychopathology and headache syndromes. Curr Opin Neurol 1995;8:248-51.

21 Silberstein S, Lipton R. Chronic daily headache. Curr Opin Neurol 2000;13:277-83.

22 Dowson AJ. Analysis of the patients attending a specialist UK headache clinic over a 3-year period. Headache 2003;43(1):14-8

23 Zelen M. A new design for randomized clinical trials. N Engl J Med 1979;300(22): 1242-5.

24 Zigmond A, Snaith R. The Hospital Anxiety and Depression Scale. Acta Psychiatr Scand 1983;67:361-70.

25 Lewis G, Wessely S. A Comparison of the General Health Questionnaire and the Hospital Anxiety and Depression Scale. Br J Psychiatry 1990;157:860-4.

26 Jenkins $R$, Lewis $G$, Bebbington $P$, et al. The national psychiatric morbidity surveys of Great Britain -initial findings from the household survey. Psychol Med 1997;27:775-89.

27 Salkovskis PM, Warwick HM. Morbid preoccupations, health anxiety and reassurance: a cognitive-behavioural approach to hypochondriasis. Behav Res Ther 1985;24:597-602.

28 Lucock MP, Morley S. The Health Anxiety Questionnaire. Br J Health Psychol 1996; 1:137-50. 
29 Beecham J, Knapp M. Costing psychiatric interventions. In: Thornicroft G, Brewin CR, Wing J, eds. Measuring mental health needs, 2nd ed. London: Gaskell, 2001:200-24.

30 Weinman J, Petrie KJ, Moss-Morris R, et al. The illness perception questionnaire: a new method for assessing the cognitive representation of illness. Psychol Health 1996;11:431-45.

31 Jenkinson C, Coulter A, Wright L. Short form 36 (SF36) health survey questionnaire: normative data for adults of working age. BM 1993;306: 1437-440.
32 Holroyd KA Andrasik F, Westbrook T. Cognitive control of tension headache. Cogn Ther Res 1997; 1:121-33.

33 Netten A, Dennett J. Unit costs of health and social care. Canterbury, UK: Personal Social Services Research Unit, University of Kent at Canterbury, 1997.

34 Simes RJ. An improved Bonferroni procedure for multiple tests of significance. Biometrika 1986:73:751-4.

35 Sudlow C. US guidelines on neuroimaging in patients with non-acute headache: a commentary. J Neurol Neurosurg Psychiatry 2002;72:ii16-8.

HISTORICAL NOTE

\section{The case of Cassian $\mathrm{H}$ in 1893 and his importance to the history of the extrapyramidal movement} disorders

A the years 1893 and 1896 the neuropsychiatrist Gabrie Anton (1858-1933) reported on the role of the basal ganglia in choreic movements. ${ }^{12}$ He described the case of a boy with choreoathetosis and suspected isolated changes in the corpus striatum to be the cause. Until then, theories of normal brain function were not prominent and clinical disorders were poorly described. The explanations of Otto Kahler (1849-1893), Arnold Pick (1851-1924) ("Pyramidenreiztheorie"), and Jean-Martin Charcot (18251893) (the existence of choreabundles) were not accepted generally.

Today, Anton's name is known by Anton's syndrome and the Anton-von Bramannsche Balkenstich method.* Although Anton's contribution to research on basal ganglia disorders is less well known, undoubtedly it represents an important advance in the systematic research of movement disorders initiated by Oskar Vogt (1870-1959) and especially by Cécile Vogt (1875-1962) at the beginning of the 20th century. Anton's attempts were developed as a pathophysiological explanation concerning the causal relationship between changes in the striatum and the development of choreoathetosis.

\section{The case of Cassian $\mathrm{H}$}

In 1891, Anton became an associate professor of psychiatry and neuropathology in Innsbruck. From there he reported the case of the 9 year old Cassian Huber, son of a farmer, whom he had examined in the department of psychiatry. At the age of 9 months the patient was taken ill with scarlet fever and suddenly, one week later, general hyperkinesis was evident. This early physical and mental development had not been disturbed. Anton described involuntary movements in the extremities on both sides. First, he believed it was a generalised chorea but had difficulty in distinguishing the choreiform and the typical athetotic movements. Muscle tone was normal and paraesthesiae lacking. The pathologicalanatomic examination after death from scarlatina only showed bilateral lesions of the striatum. In the lenticular nuclei of the putamina, the grey matter had dissolved and, in between, white matter was visible. The pyramidal tract appeared intact. He suspected the isolated lesions in the putamina to be the cause of the choreoathetosis, resulting from vascular underperfusion after an infectious disorder, perhaps with a hereditary disposition.

\section{The contribution to research on the functions of the basal ganglia}

Taking into consideration the clinical symptoms and the neuropathological findings in the case of Cassian H, Anton suspected the complex interaction of the basal ganglia had been disturbed. He concluded that, through the absence of inhibition of movement, the necessary precondition for normal movements disappeared. He assumed the involuntary movements were caused by the isolated changes in the corpus striatum. Furthermore he concluded that, because of the existence of an intact pyramidal tract, an extrapyramidal tract must also exist.

Anton's first description of the changes in the striatum was later named status marmoratus (état marbré) by Cécile Vogt.
She discovered the relationship between this and the extrapyramidal movement disorders. Cécile Vogt reported several case studies portraying similarities and from this is derived the term "syndrôme du corps strié". The status marmoratus in the striatum (Vogt's syndrome) was considered the cause of double athetosis (athétose double) in childhood. Cécile Vogt, with her husband Oskar Vogt, subdivided the basal ganglial disorders on the basis of the characteristic neuropathological lesions. ${ }^{4}$

The neurologist Alfons Jakob (1884-1931) referred to the differences between the case of Cassian $\mathrm{H}$ and other patients with status marmoratus. ${ }^{5}$ In contrast to Vogt's description, Cassian $\mathrm{H}$ showed normal development after birth. Later, after scarlatina in the ninth month of life, the involuntary movements were observed for the first time.

The characteristic history in the case of Cassian $\mathrm{H}$ supports the possibility of a post-infectious, autoimmune mechanism. On views current today, it is possible Cassian $\mathrm{H}$ suffered from the condition described in 1686 by Thomas Sydenham (16241689) and now named Sydenham's chorea. Another early medical description of chorea was given by the Dutch physician Steven Blankaart (Stephanus Blancardus, 1650-1704) in his Lexicon Medicum Greco-Latino-Germanicum in $1696 .{ }^{\circ}$

With his work on the functions of the basal ganglia, Anton made an important contribution to the research of movement disorders.

*One of Anton's most renowned scientific achievements was the Anton-von Bramannsche Balkenstich method. In collaboration with the surgeon Gustav von Bramann (1854-1913), he proposed a new clinical procedure for the treatment of hydrocephalus: the Balkenstich method. ${ }^{3}$ This operational procedure was recommended to release pressure in hydrocephalus.

E Kumbier, K Haack
Department of Psychiatry and Psychotherapy, Rostock University, Germany

Correspondence to: Ekkehardt Kumbier, Department of Psychiatry and Psychotherapy, Rostock University, Gehlsheimer Straße 20, D-18147 Rostock, Germany; ekkehardt.kumbier@medizin.uni-rostock.de

Competing interests: Although Professor Didier Leys is an associate editor of the journal the manuscript was handled by Professor Martin Rossor, editor in chief. Didier Leys did not participate in any stage of the editorial process for this manuscript.

\section{References}

1 Anton G. Ueber die Betheiligung der basalen Gehirnganglien bei Bewegungsstörungen und insbesondere bei der Chorea mit Demonstrationen von Gehirnschnitten. Wiener klinische Wochenschrift 1893;6:859-61.

2 Anton G. Ueber die Betheiligung der grossen basalen Gehirnganglien bei Bewegungsstörungen und insbesondere bei Chorea. Jahrbücher für Psychiatrie und Neurologie 1896;XIV:141-81.

3 Kumbier E, Haack K. Gabriel Anton's (1858-1933) Contribution to the History of Neurosurgery. J Neurol Neurosurg Psychiatry 2005;76:438-41.

4 Vogt C, Vogt O. Zur Lehre der Erkrankungen des striären Systems. Journal für Psychologie und Neurologie 1920;25:631-846.

5 Jakob A. Die extrapyramidalen Erkrankungen mit besonderer Berücksichtigung der pathologischen Anatomie und Histologie und der Pathophysiologie der Bewegungsstörungen. Springer, Berlin, 1923.

6 Rektor I. Chorea Sancti Viti in Lexicon medicum anno 1696. J Neurol 2003;250:7-9. 